\title{
Cleft Sentences in Spoken Arabic of Iraq
}

\author{
Tawfeeq Abdulameer Hashim AL-Ghazali \\ Department of English language, Islamic University College, Najaf, Iraq
}

Email address:

gazali.tawfeeq@gmail.com (T. A. Hashim AL-Ghazali)

\section{To cite this article:}

Tawfeeq Abdulameer Hashim AL-Ghazali. Cleft Sentences in Spoken Arabic of Iraq. International Journal of Language and Linguistics. Vol. 4, No. 1, 2016, pp. 25-29. doi: 10.11648/j.ij11.20160401.14

\begin{abstract}
This study is mainly concerned with cleft constructions as one of the grammatical devices used to highlight certain elements of the sentence or to emphasize a particular idea. The language user should be aware of the elements that can be highlighted and how he can highlight the proper element that serves to give the new information or the particular idea. Itcleft construction has been studied both as a focusing device and thematizing device. The construction is of interest in studies of information structure because it allows a speaker / writer to spread the information of a single proposition over two clauses and, consequently, two information units. It is normally assumed that the cleft construction is a means of steering the focus towards the clefted constituents. The it-cleft can have various types of phrases and clauses as its focus. This study adopts two models of analysis given by Halliday (1994) and Prince (1978) to explore the intricacies of spoken Arabic of Iraq. To the best of my knowledge this study has not been tackled yet; therefore; the present study is an attempt to fill such a gap.
\end{abstract}

Keywords: Cleft Construction, Types of Clefts, the Structure of It Cleft, the Information Structure of It Cleft, Discontinuous Cleft, Marked and Unmarked Theme

\section{Introduction}

Arabic is a member of Semitic language family, which itself is part of the wider Afro-asiatic phylum. There are three distinct forms of Arabic: classical or Qur'anical Arabic, formal or modern standard Arabic (MSA) and spoken or colloquial Arabic. There are many dialects of Arabic that differ not only from one country to another, but from one region to another in the same country. Iraqi Arabic is centralized in Iraq, with $80 \%$ of its over 20 milion people reportedly speaking Arabic. I would analyze cleft sentences of my dialect that is spoken in AL-Kufa city (about $170 \mathrm{~km}$ south of Baghdad and its population more than 110, 000). The researcher has chosen this topic so as to analyze such features of the Iraqi dialect. This study focuses on spoken rather than written language to emphasize or highlight certain elements in the sentence.

\section{Cleft Constructions}

Cleft construction is a complex sentence structure consisting of a matrix clause and a relative clause. The it- cleft construction is generally accepted to be a marked syntactic biclausal option which expresses a simple semantic proposition; in terms of information structure, the construction places an element in focus position, within a copular matrix clause. This element receives an exhaustive interpretation.

The notion of cleft construction has been defined in rigorous ways. Quirk et al, (1985: 89) define the cleft sentence as one of the grammatical means similar to and associated with information focus, it enables the user to select (with in limits) which element of the sentence will be highlighted. The cleft sentence consists of two (main) parts; an initial focal element, followed by a background structure which is similar to relative clause.

For Chalker (1984: 260) and Crystal (1990: 210) the cleft sentence is used to emphasize a certain element of a sentence which often starts with an introductory IT followed by BE with the result of a complex sentence (with two finite verbs).

Similarly, Lambrech (2002: 1) looks at the cleft construction as a complex sentence construction consisting of matrix clause and a relative clause.

As for Swan (1996: 114) and Eastwood and Mackin (1989: 193), they state that we can emphasize particular words and expressions putting every thing into a kind of relative clause except the words we want to emphasize.

Here are some examples which illustrate what has been mentioned.

1. John brought his new car last night. (SVOA).

The subject, object and the adverbial can be emphasized 
respectively by using the cleft construction.

2. It was John who brought his new car last night.

3. It was his new car that john brought last night.

4. It was last night that John brought his new car.

(Close, 1975: 67)

Prince (1978: 883-4) draws a distinction between sentences (6 and 7) and non-cleft sentence (5) as in:

5. John lost his keys.

6. What John lost was his keys.

7. It was his keys that John lost.

They are all cognitively synonymous each being true if and only if the other two are true; they therefore have the same objective information content.

\section{Pseudo Cleft}

According to Quirk \& Greenbaum, (1973: 416) and Leech and Svartvik (1975: 180), pseudo cleft refers to another type of cleft sentences. It is essentially an SVC sentence pattern with a nominal relative clause as subject or complement. Like the cleft sentence, the pseudo cleft makes the same separation between given and new information, given and new part of the communication. Winograd (1983: 508-9) explains that the pseudo-cleft is another phenomenon of cleft structure that allows nearly any combination of the elements of the clause to appear at front or back. The main verb of a pseudo cleft sentence is "be" but, instead of having it as the subject a nominalized relative clause is created. Dummy verbs like do can be used to enable the subject and verb to appear in different halves.

In spite of the fact that cleft sentence needs to change the verb to the non-finite form, and substituting "do" for it in the second part of the sentence in order to place the focus on the verb, the pseudo cleft sentence allows to place focus on the verb or the predication. Quirk \& Greenbaum, (1973: 416).

8. What he's done is (to) spoil the whole plan.

Sometimes, the wh-clause consists of verbs in the perfective or progressive aspect; in such conditions, the complement also matches that aspect.

9. What she's done is ruined the economy.

10. What they are doing is cleaning the room. (ibid)

\section{The Structure of It Cleft}

Jesperson (1969: 73: 4) state that cleft sentences start with "IT" in sentences such as:

11. It is the wife that decides.

12. It was the colonel that I was looking for.

This means that the only person who decides is the wife and the colonel is the man I was looking for. The relative clause should belong to "it" rather than to the predicative following "it is" or "it was".

The construction it is or it was serves as a demonstrative gesture to put at one particular part of the sentence to which the attention of the hearer is to be drawn especially.

The construction of it clefts consists of two parts: a superordinate clause and subordinate clause or more precisely, a relative clause, this effect recognized that it-clefts construction serves to focus the element (s) in post copular position. So the structure of it- cleft is $\langle$ it $\rangle\langle$ to be $>$ $<$ highlighted element $><$ relative element $><$ clause $>$.

(Kaltenbock, 1993: 7)

This structure is different from the simple sentence or the non- cleft sentence. The difference lies, as Prince (1978: 884), maintains, in what is called FOCUS and PRESUPPOSITION.

Prince, in this follows Chomsky (1970: 122) and others. We may say that (6 and 7)

Logically presuppose the position conveyed by (13).

13. John lost something.

The criterion for presupposition used here is the one frequently used in transformational grammar: "a sentence presupposes a sentence henceforth (S) just in case S logically implies $S$ and the negation of $\sim \mathrm{S}$, also logically implies $\mathrm{S}$ "

(Kennan, 1977: 45)

To see $(6-7)$ presuppose $(13)$ but that (5) does not. We have only to consider the negations of $14-16$.

14. John didn't lose his keys.

15. What John lost wasn't his keys.

16. It wasn't his keys that John lost.

(Prince 1978: 884)

The fact that each of the clefted forms John has lost something as presupposition and his keys as its focus has led many linguists of otherwise views to agree that wh- cleft and it- clefts assume that they are synonymous, share the same presuppositions, answer the same questions and in general they can be used interchangeably.

\section{The Information Structure of It Clefts}

The most common assumption about the information structure of it-clefts is that clefted constituents new, often contrastive information (Biber et al 1999: 959). The subordinate clause typically conveys presupposed information (Prince 1978: 896). She calls this stressed focus it-clefts, thereby indicating the discourse function of clefts, namely to give special focus to the clefted constituent. Gundel (2002: 118) refers to this information structure in clefts as prototypical. Similarly, Collins (1991: 84) follows Halliday in claiming that this information structures the unmarked type of it-clefts --- the theme new combination is unmarked; the construction creates, through predication, a local structure the superordinate clause in which information focus is in its unmarked place, at the end. This is illustrated in the table (1) from Halliday (1994).

Table 1. Marked and unmarked theme.

\begin{tabular}{lll}
\hline & Unmarked & Marked \\
\hline \multirow{3}{*}{ Non-nominalized } & You were to blame & You were to blame \\
& Theme Rheme & Theme Rheme \\
& Given New (focus) & New Given \\
Nominalized & It's you who were to blame & $\begin{array}{l}\text { It's you who were to } \\
\text { blame }\end{array}$ \\
Predicated & Theme Rheme & Theme Rheme \\
Theme & New Given & Given New (focus) \\
\hline
\end{tabular}


Table (1). Marked and unmarked information focus combined with unpredicted theme. (Halliday, 1994: 301).

The term "unmarked" here does not, however, reflect quantitative data in Collins's comprehensive study of cleft constructions, (1991: 111), it-clefts have a new clefted constituent and a given cleft clause, although the clefted constituent is new in a clear majority of cases.

Another type of information structure in it-clefts is described by Prince (1978) and others after her: Collins (1991), Delin and Oberlander (1995), Johansson(2002), namely the informative presupposition cleft, in which the cleft clause conveys new information.

\section{Types of It-Clefts}

In her discussion of cleft sentence Prince (1978: 896), concludes that it-clefts should be divided into two subclasses:

The stress focus it-cleft and the information presupposition it-cleft.

Prince (1978: 896) and Declerck (1984a: 243) distinguish two different types of information. Presupposition cleft: cleft and non-cleft. With the same line, Kaltenbock (1993: 7-8) makes them three: contrastive cleft, unstressed Anaphoric Focus cleft (UAF cleft) and Discontinuous cleft.

\subsection{Contrastive Cleft}

According to Prince (1978: 888-9) this type has a focus or (highlighted element) which is new and heavily stressed. The $\mathrm{WH} /$ that clause, on other hand is only weakly stressed and contains information that is given in the sense that "the wh /that-clause pursues the thematic line of the stretch of discourse in which it is couched" Declerck,

(1984b: 264). In other words, the clause represents a "continuous topic".

The highlighted Noun phrase (NP), because it is heavily stressed is not only strongly contrastive but also likely to be an "important topic".

17. It isn't higher prices but changed expectations that have caused people to buy more at the present time. (Murcia, 2004: 7).

\subsection{Unstressed-Anaphoric-Focus Cleft}

Prince (1978: 896) calls this type informative, presupposition, which is unlike the previous type. The Unstressed- Anaphoric- Focus (UAF) cleft has wh / thatclause conveying information which is new. The focus NP or (highlighted NP) on the other hand, is anaphoric and therefore a continuous topic. Since the highlighted element is anaphoric and continuous, this type of cleft cannot occur at the beginning of a stretch of discourse. It needs a preceding context containing the antecedent of the anaphora.

As the name suggests, the highlighted NP is unstressed, which is perfectly in line with the fact that it is anaphoric and not strongly contrastive. The wh/ that-clause is normally (vs. weakly) stressed.

18. It was in 1979 that Piet Kornhof rather boldly announced, Apartheid is dead. Murcia, (2004: 7).

\subsection{Discontinuous Cleft}

Kaltenboek (1993: 8) points out that in discontinuous cleft both the highlighted element and the relative clause are new.

Consequently, both constituents receive at least normal stress.

Thus, the main difference between the three types is that contrastive it-cleft consists of an old relative clause and a (possibly continuous) highlighted element representing new information, whereas UAF It-cleft has a new relative clause and a weakly stressed continuous highlighted element; discontinuous It-cleft involves a relative clause and a highlighted element that are both new and discontinuous (ibid).

\section{Arabic Sentence Structure}

There are two types of sentences in Arabic: nominal and verbal.

Nominal sentences begin with a noun or pronoun,

For example: Osman yektubu al-darsa. (Osman writes the lesson).

Osman yektubu al-darsa

Osman writes The lesson

While verbal sentences begin with a verb:

yektubu Osman al-darsa. (writes Osman the lesson).

Yektubu Osman al-darsa

Writes Osman the lesson

Nominal sentences have two parts: subject (mubtada'a) and predicate (xabar). Arabic sentences don't have(verb to be) because it is implied and understood from the context, although it can be confusing to some of non-Arabic speaker who used to having a verb in each sentence. The subject of the nominal sentence is a noun or pronoun, while the predicate can be a noun, adjective, preposition and pronoun or verb.

Verbal sentences begin with verb and they have at least a verb and subject. The subject can be indicated by conjugation of the verb, and not written separately. a'amal

(I work.), deresna (we studied), abi y'amal fi al tijara (my father works in trade). Some people prefer verbal sentence to nominal sentence, whenever a verb needs to be used in the sentence, however, this is not necessarily the case and the choice of which word to use at the beginning of the sentence depends on what you want the focus of the sentence to be:

abi y'amal fi altijara or y'amal abi fi al tijara.(my father works in the trade).

Abi Y'amal fi al- tijara

My father works in the trade

$Y$ 'amal abi fi al-tijara. (works my father in the trade)

Y'amal abi fi al- tijara

Works my father in the trade

\section{Models of Analysis}

This study adopts two models i.e., Halliday (1994) as well as Prince (1978), as a technique of analysis to explore the 
complex the complexity of selected data.

According to Prince (1978), the sentence is divided into two parts; the sentence takes its name from the fact that the single clause of the basic sentence pattern (wh-cleft) is split into two clauses.(we recognize a clause by presence of subject and verb). The wh-cleft is a sentence that splits the basic clause into two parts with, one of the sentence's parts beginning with a word that starts a $w h$. For example, John sent Mary a letter, it can be created several different wh sentences of similar meaning:

Grammar subject verb complement

Meaning theme process goal

Example: EN. What John sent to Mary was the letter

It clefts allow speakers / writer another types of sentence that splits the basic clause pattern into two parts. The theme in this sentence pattern is an "empty" function word, a pronoun "it" that really has no meaning like an ordinary pronoun since, it refers to nothing. Instead, the it cleft allows the writer/ speaker to focus on the actor in the first example below:

Grammar subject verb complement

Meaning theme process focus on actor

Example: EN. It was John who sent the letter to Mary.

Grammar subject verb complement

Meaning theme process focus on goal

Example: EN. It was the letter that John sent to Mary.

In systemic linguistics the grammatical subjects in it-cleft and wh-cleft sentences above are called "marked" themes since those sentences do not begin with the expected, common, ordinary subject of the basic clause pattern(which is called the "unmarked" theme). Another type of marked theme can be seen below, a type characterized by the use of the grammatical object at the beginning of the sentence.

Grammar direct object subject verb adverbial

Meaning goal actor action recipient

Example: EN. The letter John sent to Mary.

In the example above, the direct object (the letter) hold the focus of attention as it takes the lead in the sentence.

\section{Data Analysis}

The following are analyzable examples of my colloquial Iraqi dialect to be analyzed according to Prince and Halliday.

Ex: 1. Arc. Wahida hiyya illi rabahat alja?iza.

EN. It was Wahida who won the prize.

Wahida hiyya illi rabah a t al Ja'iza

Wahida She who win past F M The prize

Ars. Wahida rabahat alja'iza.

En. Wahida won the prize.

Grammar: subject verb complement

Meaning: theme process focus on the actor

Example: Arc. Wahida__ hiyya illi rabahat alja'iza.

The example shows that the subject "Wahida" hold the focus of attention and the pronoun "hiyya" adds assertive to the subject. In Iraqi dialect the relative pronoun "illi" refers to both genders feminine and masculine (singular or plural) while in "MSA" is different. The verb "rabaha" is built on the "fath" which appears in Iraqi dialect as " $a$ " attached to the verb so as to carry the past tense marker and the " $t$ " sound at the end of the verb carries the feminine marker which is called "taa alt'ni:th al-sakinah" in (MSA).

Ex: 2. Arc. Howa Ahmed illi yaftah al-mahal yawmiyya.

En. It is Ahmed who opens the shop daily.

Howa Ahmed illi ya ftah al mahal yawmiyya

He Ahmed who PMM open the shop daily

Ars. Ahmed yaftah al-mahal yawmiyya.

En. Ahmed opens the shop daily.

Grammar: subject verb complement

Meaning: theme process focus on the actor

Example: Arc. Howa Ahmed illi yaftah al-mahal yawmiyya.

In this example the pronoun "howa" precedes the subject to add another emphasis to the actor. It is seen that the pronoun gives the emphasis when it precedes or follows the subject. The prefix "ya" carries both the present tense and the masculine marker when attached the verb "yaftah".

Ex: 3. Arc. Mu sayyara illi ishtaraha Sameer amis.

En. It wasn't a car that Sameer bought yesterday.

$\mathrm{Mu}$ Sayyara illi ishtara ha Sameer amis

Not car that bought OM Sameer Yesterday

Ars. Sameer ma ishtara sayyara amis.

En. Sameer didn't buy a car yesterday.

Grammar: subject verb complement

Meaning: theme process focus on the goal

Example: Arc. $\mathrm{Mu} \_$sayyara illi ishtaraha sameer amis.

By the negation and fronting the example shows the focus on the object (sayyara) which is the goal of the sentence. The verb "ishtara" ends with what we call in (MSA) alif maqsurah, in this case there is no past marker appears because it is difficult to pronounce. The suffix "ha" refers to the object.

Ex: 4 Arc. Ma galata Nadya howa il-sidig.

En. What Nada said was the truth.

Ma gal a $t$ a Nadya howa il sidig

What say Past FM OM Nadya he the truth

Ars. Nadya galat il-sidig.

En. Nadya said the truth.

Grammar: subject verb complement

Meaning: theme process focus on the goal and the actor Example: Arc Ma galata Nadya howa il- sidig.

The example shows that the focus falls on the actor (Nadya) and the goal (il-sidig). the pronoun "howa" refers to "il-sidig" and not to the subject because in Arabic language the things are treated as feminine or masculine. So, the pronoun "howa" adds a strong emphasis to the goal of the sentence.

Ex: 5 Arc. Ma nitmanna howa il adil.

En: what we wish is the justice.

Ma ni tmanna howa il adil

What P1(PL) present wish he the justice

Ars. Nitmanna il-adil.

En. We wish the justice.

Grammar: subject verb complement

Meaning: theme process focus on the goal 
Example: Arc. Ma nitmanna howa il-adil

The example splits the clause with emphasis on the goal. The verb "nitmanna" contains the prefix "ni" which refers to the first person and plural marker as well as the present tense. On the other hand we can say that "ni" refers to the subject pronoun "nahn" In this example it is difficult to non-native Arabic speaker to understand the sentence if we omit the pronoun "howa" because the meaning would be opposite.

\section{Conclusion}

English as an / indo-European language/ and Arabic are completely different in their forms, but they share the same universals of language according to the data analysis about cleft sentence and pseudo cleft sentence in colloquial Iraqi language. In it-cleft the expression occurs initially i.e. subject position while in the pseudo cleft it occurs in the final position of the sentence. The relative clause in the it-cleft is not a surface subject (and does not occur in sentence initial position), we expect that it will not refer to the topic as consistently as the relative clause in the wh-cleft. In fact, the relative clause in it cleft is often stressed and in such instances it is interpreted as part of the new information asserted or questioned in the sentence.

\section{Abbreviations}

$\begin{array}{ll}\text { Symbol } & \text { Description } \\ \text { Arc } & \text { Arabic cleft } \\ \text { Ars } & \text { Arabic sentence } \\ \text { En } & \text { English } \\ \text { MSA } & \text { Modern Standard Arabic } \\ \text { P1(PL) } & \text { First person and plural } \\ \text { S } & \text { Sentence } \\ \text { SVC } & \text { Subject + Verb + Complement } \\ \text { SVOA } & \text { Subject }+ \text { Verb }+ \text { Object }+ \text { Adverb } \\ \text { FM } & \text { Feminine Marker } \\ \text { PMM } & \text { Present, Masculine Marker } \\ \text { OM } & \text { Object Marker }\end{array}$

\section{References}

[1] Biber, D., S. Johanson, G. Leech, S. Conrad and E. Finegan (1999), Longman grammar of spoken and written English. London: Longman.

[2] Chalker, Sylvia, 1984. Current English Grammar. Cambridge: Cambridge University press.

[3] Chomsky, Noam.1970. Deep Structure, Surface Structure and Semantic Interpretation. New York: Harcourt Brace \& World.

[4] Close, R. A. 1975 A Refrence Grammar for Students of English. London: Longman.
[5] Collins, P. C 1991, Cleft and Pseudo cleft Constructions in English. London and New York: Routledge.

[6] Crystal, David. 1990. Rediscover Grammar, Essex: Longman Group Ltd.

[7] Declerk, R. 1984a "the pragmatics of it clefts and wh-clefts" Lingua 64: 251-289.

[8] Delin, J. and J. Oberlander, 1995, "Syntactic constrains on discourse structure: The case of it-cleft". Linguistics, 33: 465500 .

[9] Eastwood, J. and Mackin, R. 1989. Basic English Grammar. Oxford: oxford university press.

[10] Gundel, J. K. 2002, "Information structure and the use of cleft sentences in English and Norwegian", in: H. Hasselgard et al. (eds). Information structure in a cross- linguistic perspective. Amsterdam: Rodopi; 113-128.

[11] Halliday, M. A. K. 1994. An introduction to functional grammar. $2^{\text {nd }}$ ed. London: Arnold.

[12] Jesperson, O. 1969. Analytic Sentence. London: Hold, R. and Wiston, Inc.

[13] Johansson, M. (2002), Cleft in English and Swedish: A contrastive study of It-clefts and wh-clefts in orginal texts and translation. $\mathrm{PhD}$ thesis, Lund University.

[14] Kaltenbock, Gunther. 1993. "A brief discussion of it- clefts in spoken texts" Internet: fb10. uni-brenen-delang listik / lang pro/ project Lgeml- lexpaper.

[15] Kennan, Edward. 1977. Two kinds of presupposition in Natural language. New York: Holt.

[16] Lambrecht, K. 2002. Varieties of Cleft Constructions and Why They Exist, Internet: http://www.psych. Wis. Edu / lang/ Abstract/ Stjohn.

[17] Leech, Geoffry \& Svartvik Jan. 1975. A Communicative Grammar of English. London: Longman.

[18] Murcia, Marianne Celce. 2004. Approaches To Teaching English Grammar with Reference to Written Discourse. Internet: http://www.exchange. State.Gov/ education long teaching/ functional Section $5 \# 5$.

[19] Prince, Ellen F. 1978. " A comparison of wh- clefts and itclefts in Discourse" Language 54: 883- 906.

[20] Quirk, R. S. Greenbaum, S. 1973. A Universal Grammar of English. London. Longman.

[21] Quirk, R. S. Greenbaum. G. Leech, and J. Svartvik 1985. A Comprehensive Grammar of the English Language. London: Longman.

[22] Swan, M. 1996. Practical English Usage. Oxford: oxford University press.

[23] Winograd, Jerry. 1983. Language as a Cognative process. New York: Addison- Wesley Publishing Company. Inc. 